\title{
Distortion Optimization of Engine Cylinder Liner Using Spectrum Characterization and Parametric Analysis
}

\author{
Zhaohui Yang, ${ }^{1}$ Baotong $\mathrm{Li}^{2}$, and Tianxiang $\mathrm{Yu}^{1}$ \\ ${ }^{1}$ School of Aeronautics, Northwestern Polytechnical University, Xian 710072, China \\ ${ }^{2}$ State Key Laboratory for Manufacturing Systems Engineering, Xian Jiaotong University, Xian 710049, China \\ Correspondence should be addressed to Baotong Li; baotong.me@mail.xjtu.edu.cn
}

Received 19 January 2016; Accepted 13 April 2016

Academic Editor: Xiangyu Meng

Copyright (c) 2016 Zhaohui Yang et al. This is an open access article distributed under the Creative Commons Attribution License, which permits unrestricted use, distribution, and reproduction in any medium, provided the original work is properly cited.

\begin{abstract}
In an automotive powertrain system, the cylinder liner is one of the most critical components which possesses the intricate structural configurations coupled with complex pattern of various operational loads. This paper attempts to develop a concrete and practical procedure for the optimization of cylinder liner distortion for achieving future requirements regarding exhaust emissions, fuel economy, and oil consumptions. First, numerical calculation based on finite element method (FEM) and computational fluid dynamics (CFD) is performed to capture the mechanism of cylinder liner distortion under actual engine operation conditions. Then, a spectrum analysis approach is developed to describe the distribution characteristic of operational loads (thermal and mechanical) around the circumference of a distorted cylinder bore profile; the FFT procedure provides an efficient way to implement this calculation. With this approach, a relationship between the dominant order of distortion and special operational load is obtained; the design features which are critically relative to cylinder liner distortion are also identified through spectrum analysis. After characterizing the variation tendency of each dominant order of distortion through parametric analysis, a new design scheme is established to implement the distortion optimization. Simulation results indicate that a much better solution is obtained by using the proposed scheme.
\end{abstract}

\section{Introduction}

In an automotive powertrain system, the cylinder liner is one of the most critical components affecting the operational performance of an engine. With the ever-increasing demand in higher efficiency of engine sealing units which involves both oil consumption and exhaust emission, the demand on improved tightness of contact on piston ring/cylinder liner interface (PRCI) is also increasing [1-3]. In addition, lower friction design is also being aggressively pursued for the tribological system (e.g., piston ring/cylinder liner) which is important for a better fuel economy [4-6]. However, the former demand (i.e., sealing efficiency) requires a higher pretightening force on piston ring which will lead to excessive engine friction losses and subsequently, resulting in an adverse effect on the fuel consumption. Therefore, higher sealing efficiency and lower engine friction losses are two conflicting goals. In this regard, cautions should be placed in the quality of the interface between piston ring and cylinder liner [7].
Due to imperfections in manufacturing and pretightening process, as well as complex pattern of various operational loads, an ideal circular cylinder bore cannot be achieved during engine operation process. Hence, the elastic piston ring should conform to the distorted cylinder bore. However, if such distortions become too large, the piston ring may be unable to fully conform to the cylinder bore, and this imperfection may influence the normal engine operation in terms of increasing component friction, wear, and oil consumption. To this end, the piston rings may achieve better sealing characteristics within a low distorted cylinder bore, and, for unchanged sealing demand, the engine friction losses could be reduced by decreasing the pretightening force on piston rings. That is, a low distorted cylinder liner opens up potentials for resolving the above conflict.

The ability to predict and optimize the geometrical distortions of cylinder liner has generated significant interest in recent years. Many analytical and computational tools have been used to attack this problem. A pioneering analytical 
work dealing with the presentation of a distorted cylinder bore profile was performed by Gintsburg [8]. In this work, the sealing characteristic of a splitless piston ring was analyzed by approximating distortions from the ideal circular shape with a Fourier series. By describing a distorted bore profile in this form, Müeller [9] further developed a set of bounds for each Fourier order of distortion, and Luenne and Ziemb [10] adopted these bounds in the development of a measurement system for evaluating the distortion characteristics of cylinder liner. Similarly, Dunaevsky [11, 12] explored a random process based scheme to present the tightness of contact on PRCI. In this scheme, a design criterion was proposed to quantify amplitude and order of bore distortions regarding the piston ring conformability. Although these studies enable complex bore geometries to be decomposed into a series of simpler distortion orders, the distribution characteristic of operational loads (thermal and mechanical) around the circumference of a distorted cylinder bore profile was not yet to be fully analyzed. A systematic approach focusing on the relationship between each Fourier order of distortion and various operational loads was not given, though this relationship may be utilized to get a better understanding for the mechanical nature of cylinder liner distortions.

As a different approach, the numerical simulation based on finite element method (FEM) is very useful to predict the three-dimensional distortions of cylinder liner. These approaches take into account pretightening force, heat transfer, and complicated combustion process which the above analytical models neglect. Soua et al. [13] proposed a classical FE model of engine structure to deal with the computation of cylinder liner distortions. However, this model was excessively simplified by using the symmetry assumptions. In fact, Maassen et al. [14] experimentally observed that both the stress fields and distortion patterns on cylinder liner are by no means axis-symmetric and rotational symmetric. With the development of 64-digit computers and refined calculation technique, several studies [15-19] further complemented the full three-dimensional FE model and simulate the physical behavior to evaluate the structural integrity of different design schemes. Although realistic distortions can be precisely captured at any interest point of cylinder liner in these studies, some critical issues for distortion optimization also remain. For instance, keeping the amplitude of the integral distortion to be the minimum does not always guarantee the best solution in the cylinder liner design. Actually, such integral distortion has long been considered as a composite of various orders of bore distortions, and different orders are sensitive to different operational loads. To truly optimize a design, detailed information for the dominant order of distortion is very important.

In summary, the following factors are vital to the success of distortion optimization:

(i) Precise prediction of the distortion patterns on cylinder liner.

(ii) Clarification of the relationship between each Fourier order of distortion and various operational loads.

(iii) Parameter characterization of design features which are critically relative to cylinder liner distortions.
In the scope of this paper, integration of the above stated factors enables reasonable evaluation of distortion patterns at the beginning. Then, information from an extensive rating of spectrum characteristic of bore distortions and operational loads can be utilized to identify the critical design features. Based on this, the parametric analysis is performed to obtain the variation tendency of each dominant order of distortion, and optimal design scheme can be achieved based on these findings.

\section{Computational Model}

To establish the analytical methodology of the distortion mechanism of cylinder liner, a line style gasoline engine, having 4 cylinders and 4 strokes, is adopted in this paper. A precise structural analysis with appropriate boundary conditions is of critical importance for the prediction of realistic distortions on cylinder liner. The first phase is to define the complex structural configurations of engine components. Figure 1 shows the FE model of the cylinder structure and water jacket. Since high temperature and stress gradients are anticipated in and around the bridge area of both the water jacket and cylinder structure, these sensitive regions are meshed with high resolution (i.e., the element aspect ratio is approximately 2.0) to precisely capture the physical behaviors occurred on the solid-fluid interface. The total numbers of the elements and nodes in the model are 601736 and 690 912, respectively. The material properties of the components taken from literature [20] are utilized in this analysis.

Because the distortion of cylinder liner is mainly caused by the thermal stress, the primary target of distortion analysis is to accurately predict the temperature distribution within cylinder structure. The thermal load of cylinder structure is mainly contributed by the heat flux from combustion gas to the cylinder wall. In an operating circle of engine, the time-averaged heat flux transferred to the cylinder wall from combustion gas could be calculated as follows:

$$
q_{m}=\frac{1}{t_{0}} \int_{0}^{t_{0}} \alpha_{\text {gas-wall }} T_{\text {gas }} d t-T_{\text {wall }} \frac{1}{t_{0}} \int_{0}^{t_{0}} \alpha_{\text {gas-wall }} d t,
$$

where $q_{m}$ is the time-averaged heat flux $\left(\mathrm{W} / \mathrm{m}^{2}\right), t_{0}$ is the operating circle time (s), $\alpha_{\text {gas-wall }}$ is the instantaneous heat transfer coefficient between the combustion gas and the cylinder wall $\mathrm{W} /\left(\mathrm{m}^{2} \cdot \mathrm{K}\right)$, and $T_{\text {gas }}$ and $T_{\text {wall }}$ represent the instantaneous temperature of the combustion gas and the cylinder wall $(\mathrm{K})$, respectively.

Among the empirical models [21-23] for calculating the instantaneous heat transfer coefficient $\alpha_{\text {gas-wall, }}$, Woschni's formula [24] is considered as the most suitable model for the gasoline engine, which is represented as follows:

$$
\begin{aligned}
\alpha_{\text {gas-wall }}= & 130 \\
& \cdot D^{-0.2} p^{0.8} T^{-0.53}\left[b v_{m}+\frac{c\left(V_{s} T_{r} / P_{v} V_{v}\right)}{\left(p-p_{0}\right)}\right]^{0.8},
\end{aligned}
$$

where $D$ is the cylinder diameter $(\mathrm{m}), p$ is the instantaneous pressure in the cylinder $(\mathrm{MPa}), T$ is the instantaneous temperature of the combustion gas $(\mathrm{K}), v_{m}$ is the time-averaged 


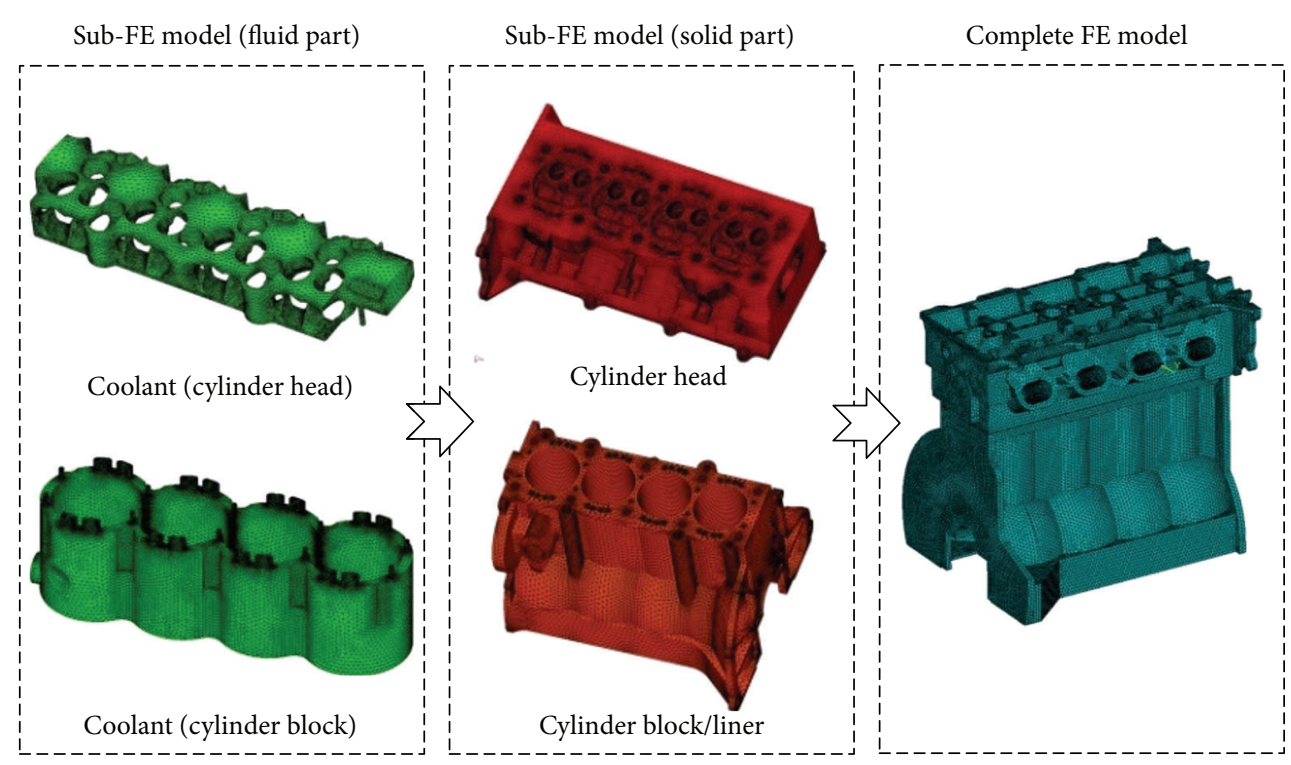

FIGURE 1: FE modeling process of engine components for the structural analysis.

speed of the piston $(\mathrm{m} / \mathrm{s}), b$ is the empirical parameter (for the intake and exhaust strokes, $b=7.14$; for the strokes of compressing, burning and expanding, $b=2.99$ ), and $c$ is another empirical parameter (for the strokes of compressing, intake, and exhaust, $c=0$; for the process of burning and expanding, $c=3.24 e-3)$.

It is necessary to determine the instantaneous pressure and temperature for the solving of the time-averaged heat flux by employing (1) and (2). In this paper, the combustion conditions including pressure and temperature are obtained through the simulation of the operational process by using KIVA3 program; for calculation details, see literature [24].

Besides the thermal boundary conditions, a modified RNG $k-\varepsilon$ turbulent model [25] is employed to simulate the turbulent flow within the water jacket. Meanwhile, to describe the pretightening effect on cylinder liner distortion, a required compressive axial load $(22 \mathrm{KN})$ is imposed on the bolt bodies, and the contact elements are applied on the interfaces between cylinder structures, bolts, and gasket.

\section{Spectrum Characterization of Bore Distortions and Operational Loads}

The interactions between structural mechanics, heat transfer, and fluid coolant are simulated through the FLOTRAN calculation module available in ANSYS ${ }^{\circledR}$. The calculation data specifies a computational grid and a distortion vector associated with each element node. The grid itself is divided into 73 hierarchies, each hierarchy having approximately 256 points. To visualize these data, the amplitude of each distortion vector is mapping onto the computational grid by using the default linear interpolation in MATLAB. Figure 2 shows the distortion patterns on the inner surface of different cylinder liners under hot firing operation condition.

Due to the small structural stiffness in the front and rear side of cylinder structure, the distortion levels of the 1st- and the 4th-cylinder liner are slightly higher than those of others. The maximum distortion of the 1st-cylinder liner $(52.6 \mu \mathrm{m})$ is located at the left side $\left(180^{\circ}\right.$ from $\left.P_{s}\right)$ of the bottom region. In contrast, the maximum distortion of the 4 th-cylinder liner $(51.4 \mu \mathrm{m})$ is located at the right side $\left(0^{\circ}\right.$ from $\left.P_{s}\right)$ of the bottom region. As for the 2 nd- and 3rd-cylinder liner, the distortion amplitude increases to the maximum value $(47.6 \mu \mathrm{m}$ and $48.1 \mu \mathrm{m})$ almost $40 \mathrm{~mm}$ away from the reference point $\left(P_{s}\right)$ and then diminishes gradually. Noting that the radius of the cylinder bore is $41.5 \mathrm{~mm}$, the maximum distortion represents less than $0.27 \%$ of the bore radius.

In order to get a deep insight about the mechanism of cylinder liner distortion under actual engine operation conditions, the Fourier analysis used to describe the distorted bore profile $[8,9,11]$ is extended in this paper to deal with the spectrum calculation of various operational loads, such as thermal load (temperature effect) and mechanical load (pretightening effect). By imposing a polar coordinate system $(\varphi, r)$, the axis of which coincides with the center of the ideal circular bore profile, the distorted cylinder liner corresponding to various orders of bore distortions and operational loads can be mathematically expressed by the polar radius $\xi_{j}(\varphi)$ and polar angle $\varphi$, which can be written as follows:

$$
\xi_{j}(\varphi)=r_{j 0}+\sum_{\omega=1}^{N} a_{\omega} \cos (\omega \varphi)+b_{\omega} \sin (\omega \varphi)
$$

$$
(j=1,2,3)
$$

where $\xi_{j}(\varphi)(j=1,2,3)$ is the circumferential distribution of distortion, temperature, and pretightening stress, respectively; $r_{j 0}(j=1,2,3)$ is the nominal radius of the studied profile (in this paper, for distortion analysis, $r_{10}=41.5 \mathrm{~mm}$, for thermal load analysis, $r_{20}=400 \mathrm{~K}$, and for mechanical load analysis, $r_{30}=80 \mathrm{MPa}$ ); $\omega$ is the Fourier order number; $N$ is the total number of the Fourier orders; $a_{\omega}$ and $b_{\omega}$ are 


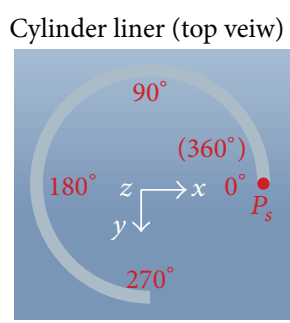

Cylinder liner (front veiw)

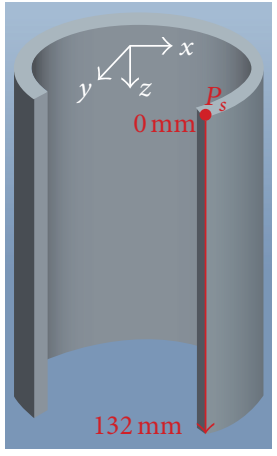

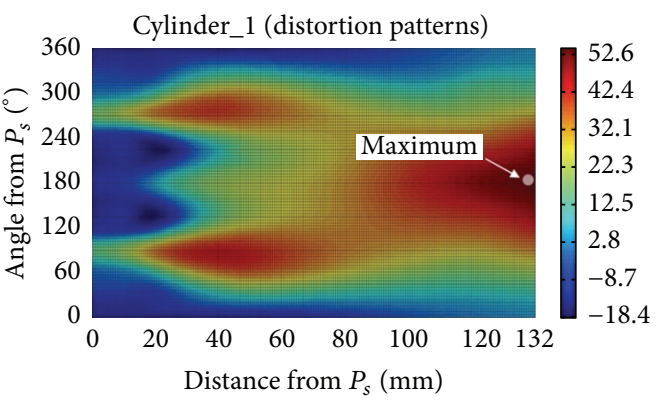

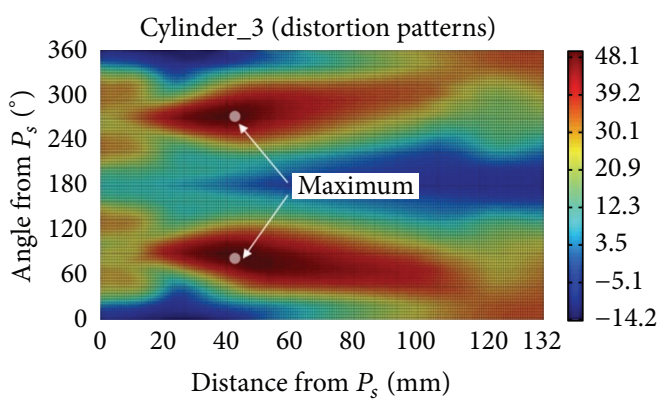

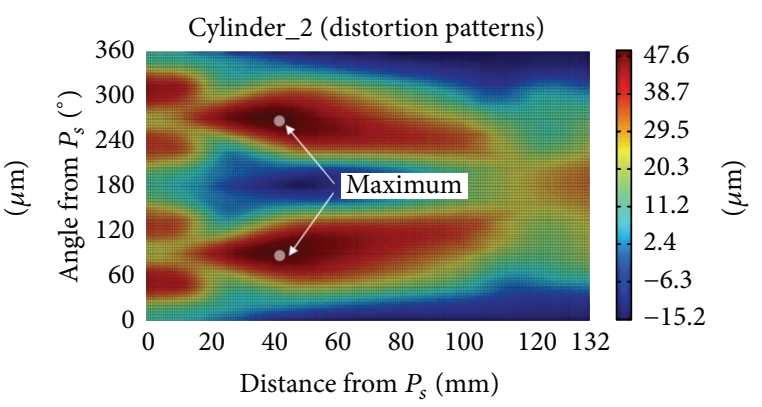

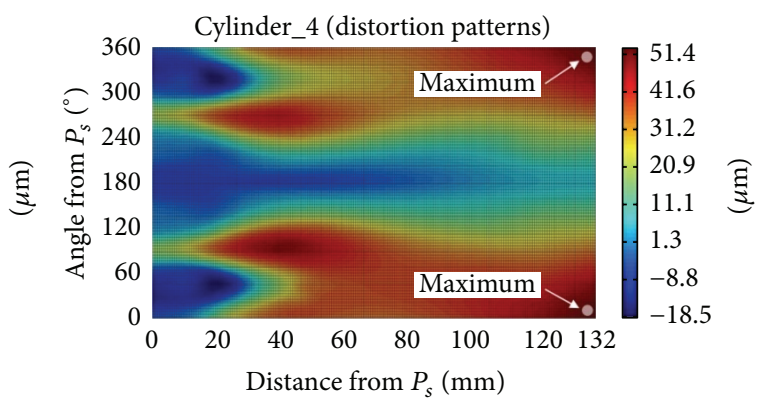

FIGURE 2: Distortion patterns on the inner surface of different cylinder liners.

the coefficients giving amplitude and phase for each Fourier order.

During the analysis, the boundary of the studied profile (distortion, temperature, and pretightening stress) is considered to be circumnavigated within a certain plane at constant speed. The size of the calculation step is determined such that one circumnavigation takes time $2 \pi$ and the number of calculation steps is $2^{\omega}$; for instance, $2^{6}=64$ steps are adopted in this research. Hence, the above stated function can be expressed alternatively in the following form:

$$
\begin{aligned}
x_{j m}+i y_{j m}= & r_{j 0}+\sum_{\omega=-64 / 2+1}^{+64 / 2}\left(a_{\omega}+i b_{\omega}\right) \\
& \cdot\left[\cos \left(\frac{2 \pi \omega m}{M}\right)+i \sin \left(\frac{2 \pi \omega m}{M}\right)\right] \\
& (j=1,2,3),
\end{aligned}
$$

where $x_{j}$ and $y_{j}(j=1,2,3)$ are the coordinates describing the circumferential distribution of distortion, temperature, and pretightening stress, respectively; $m$ and $M$ are the index number and total number of the FE data points on each hierarchy, respectively. The number of calculation steps selected dictates the number of distortion orders obtained from the Fourier analysis and therefore the level of detail described. Since there are $256 \mathrm{FE}$ data points on each hierarchy, the 64-point fast Fourier transformation (FFT) enables to provide enough accuracy for the calculation. Figure 3 shows the spectrum distribution of distortion patterns on cylinder liner, and the evolution procedure of the dominant order of distortion is also given in Figure 4.

It is evident in Figure 3 that the 2nd- and 4th-Fourier orders are the dominant distortion orders. Additionally, the 3rd-, 6th-, and 8th-Fourier orders also contribute to the cylinder liner distortion in some extent. The evolution procedure shows that the 2 nd order of distortion reaches maximum almost $40 \mathrm{~mm}$ away from $P_{s}$, and the corresponding value of the 4 th order of distortion is observed at the axial location of $20 \mathrm{~mm}$.

To clarify the factors causing the dominant order of distortion, the statistical nature of different operational loads is investigated by using Fourier analytical model. Figures 5 and 6 demonstrate the spectrum distribution of the temperature and pretightening stress, respectively. It is clear that the 2ndFourier order of temperature patterns makes the greatest contribution to the thermal effect within cylinder liner, while the 4th-Fourier order is the most significant term for the mechanical effect (pretightening stress).

By comparing the dominant orders of distortions and operational loads, it can be found that the 2nd order of cylinder liner distortion is the most sensitive to the thermal load and the mechanical load (pretightening force) is the most influential factor for the 4 th order of distortion.

According to the results from previous literatures, the 2nd order of distortion reflects the ovality of the distorted bore profile, and the 4 th order of distortion represents a clover leaf shape. In other words, excessive or inadequate cooling of the cylinder structure may cause thermal expansion differences around the circumference of cylinder bore profile which will lead to an oval distorted liner shape. Although the 2nd order of distortion is larger than the distortion caused by the pretightening force, it is difficult for piston ring to conform to the clover distorted liner shape (4th order of distortion). This is probably due to the curvature of the 4 th-order bore profile becomes greater than that of the 2nd-order bore profile. Conclusively, the core of keeping a low distorted cylinder liner is the optimization of the dominant order of distortion, 

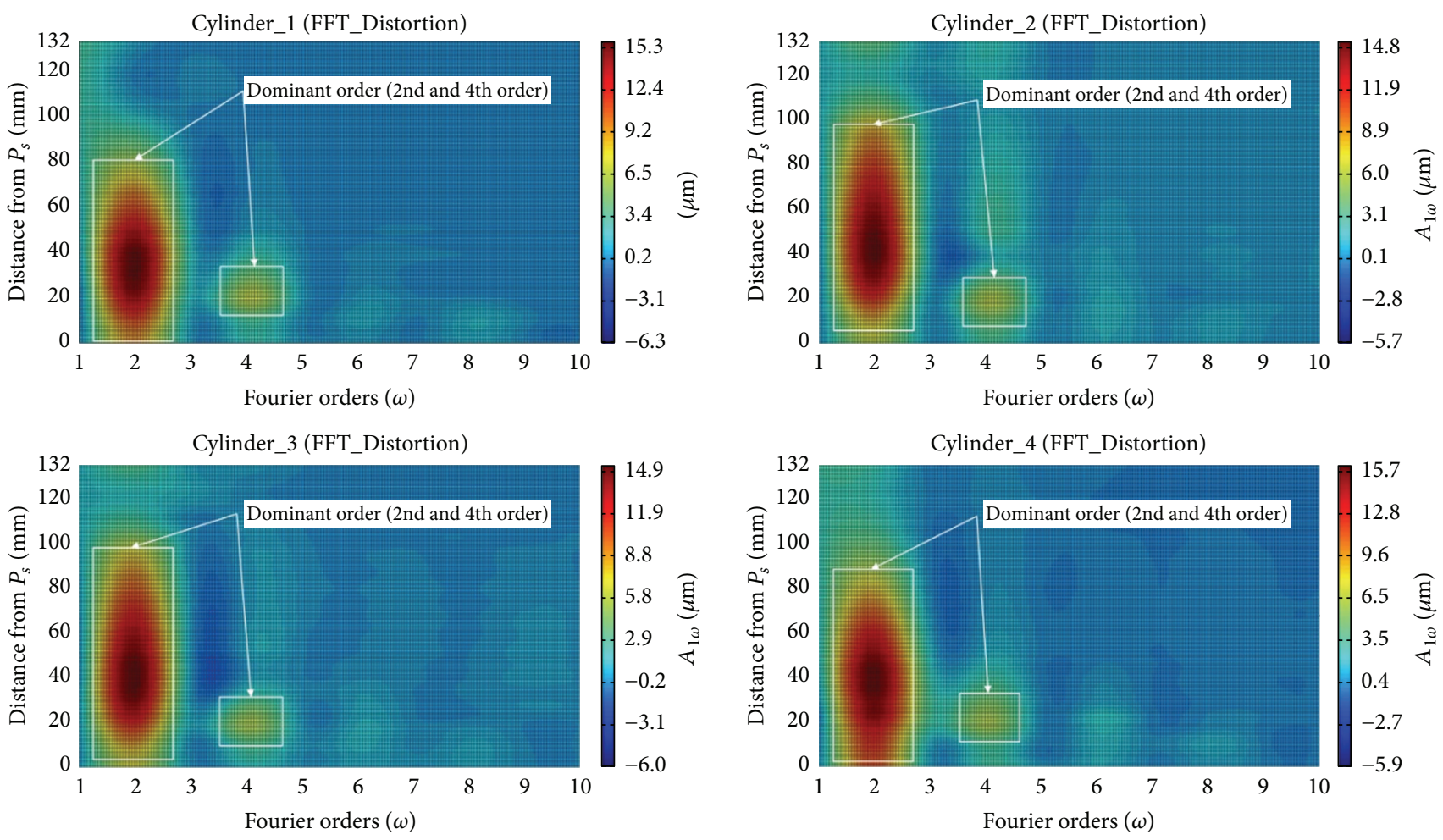

FIGURE 3: Spectrum distribution of distortion patterns on cylinder liner $\left(A_{1 \omega}\right)$.
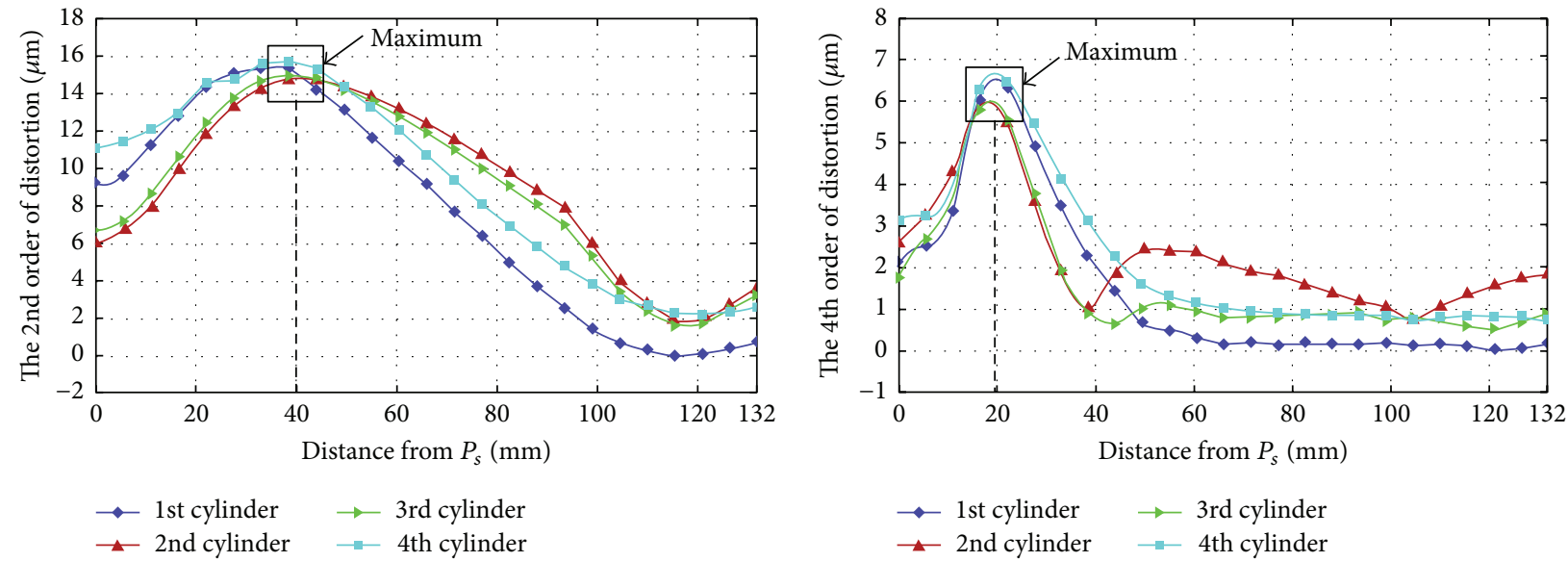

FIgURE 4: Evolution procedure of the dominant order of distortion.

which mostly ties in selecting the optimum cooling and pretightening parameters for engine operation. Therefore, a proper design scheme for water jacket and pretightening process is required to reduce such distortion.

\section{Distortion Optimization Based on Parametric Analysis}

To provide insight on the improvement potential of the modification in water jacket and pretightening process, the parametric analysis is used to study how the design parameter changes affect the resulting of cylinder liner distortion. In this study, the key parameters are denoted by specific symbols, shown as Figure 7. The upper and lower limits of these symbols are enumerated below:

$P_{1}$ : (thickness of the water jacket, initial value is $7 \mathrm{~mm}$ ) this factor may vary from $5 \mathrm{~mm}$ to $13 \mathrm{~mm}$,

$P_{2}$ : (diameter of the coolant inlet, initial value is $26.8 \mathrm{~mm}$ ) variations within $15 \%$ of its initial value are permitted,

$P_{3}$ : (height of the coolant inlet, initial value is $25 \mathrm{~mm}$ ) this factor may vary from $25 \mathrm{~mm}$ to $65 \mathrm{~mm}$, 

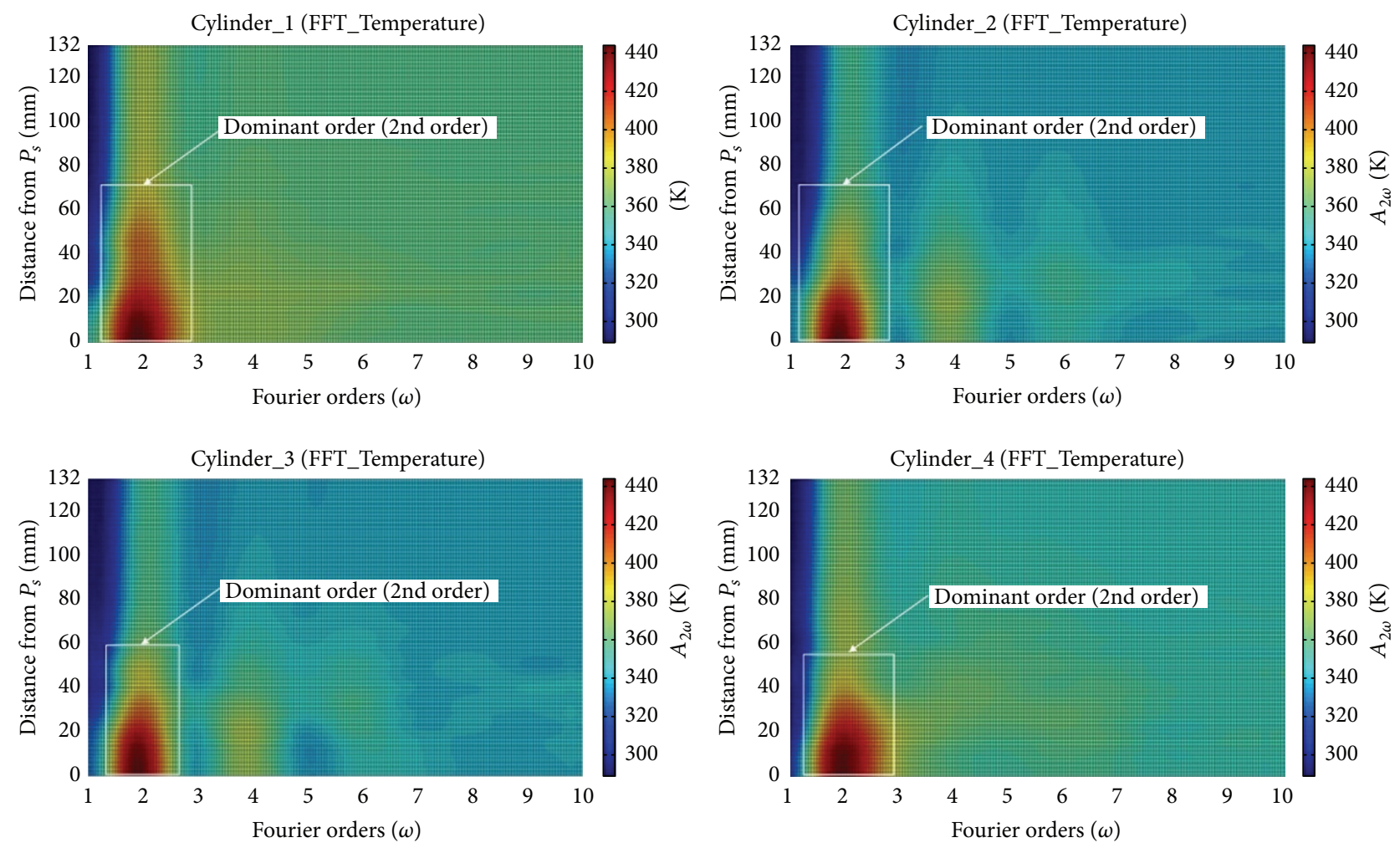

FIGURE 5: Spectrum distribution of temperature patterns on cylinder liner $\left(A_{2 \omega}\right)$.
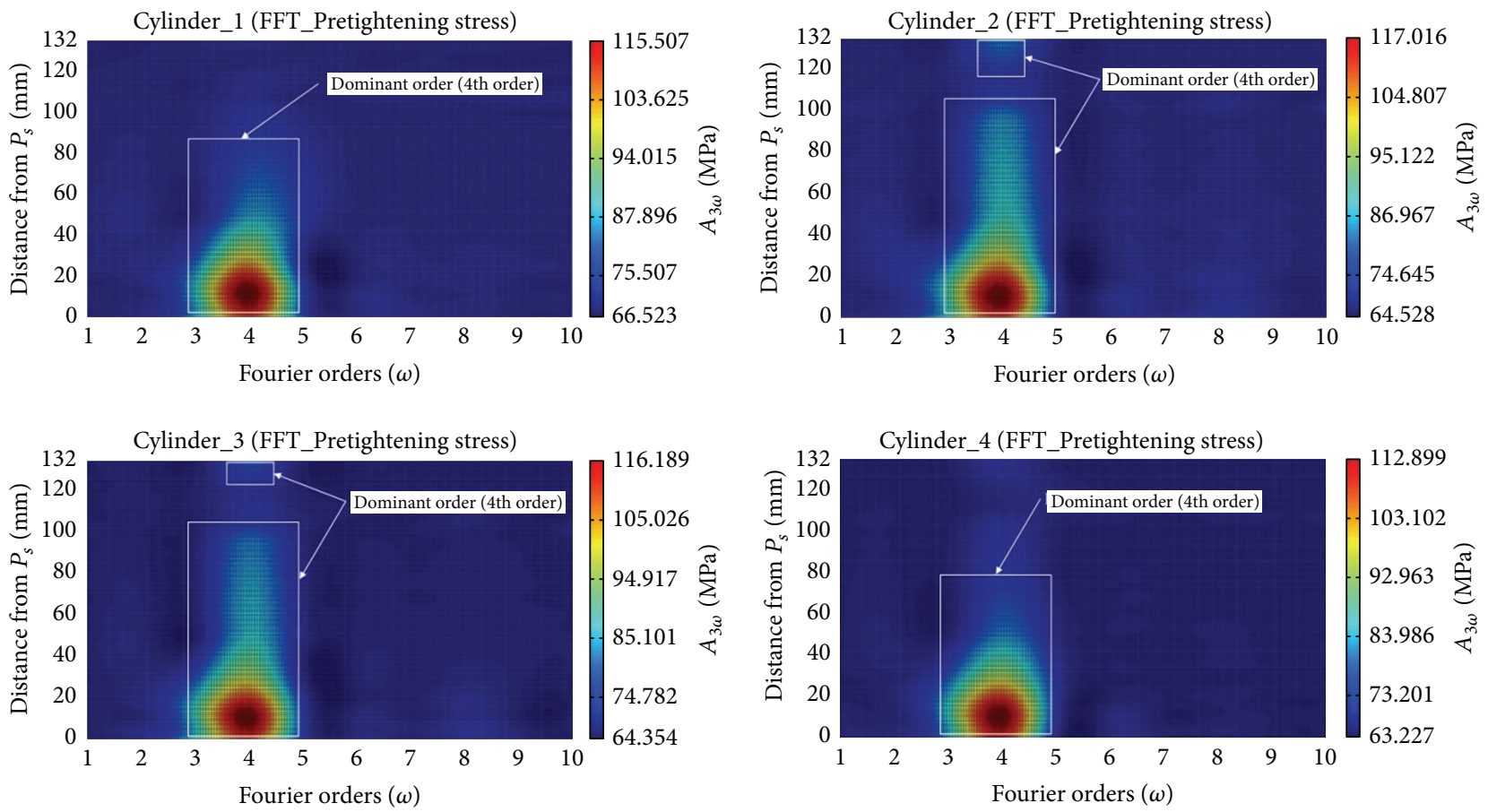

FIGURE 6: Spectrum distribution of pretightening stress patterns on cylinder liner $\left(A_{3 \omega}\right)$. 


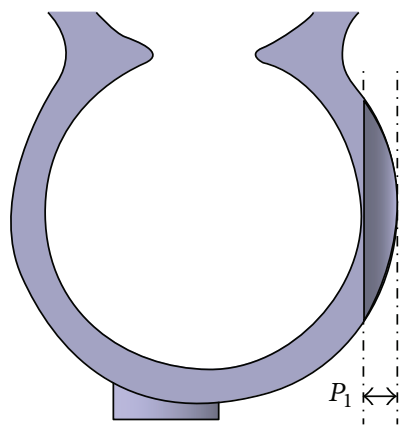

(a) Water jacket
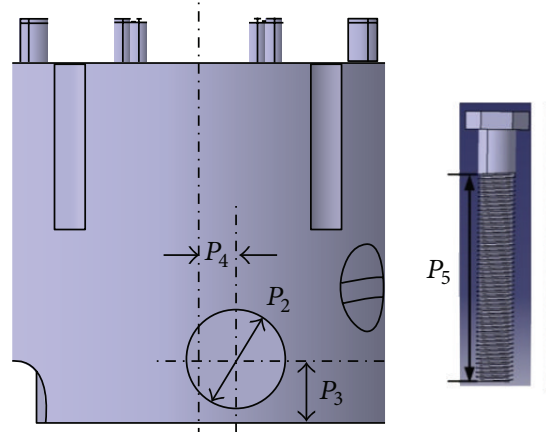

6

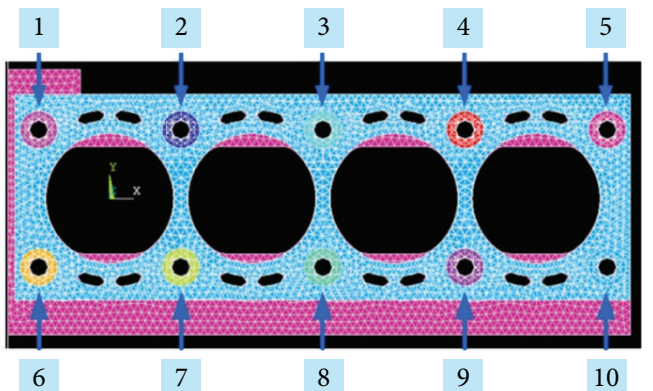

(b) Bolts and gasket

FIGURE 7: Schematic representation of the key parameters for water jacket and pretightening components.

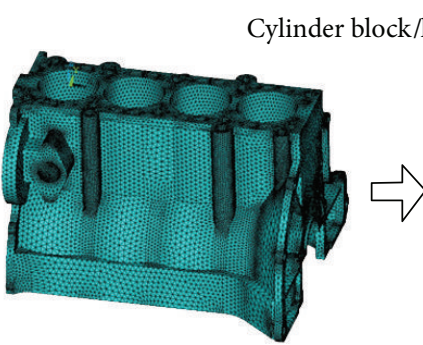

Detailed model

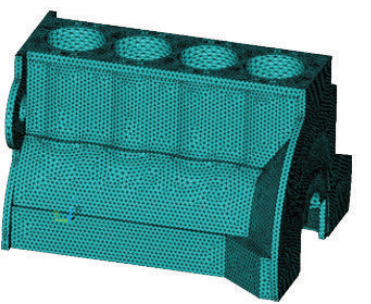

Simplified model

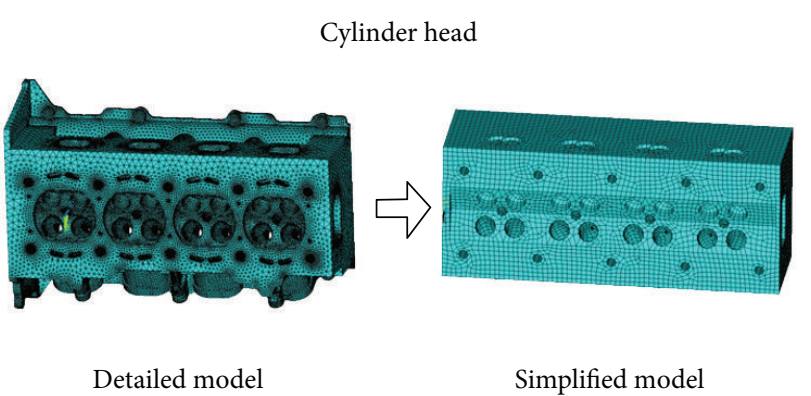

Simplified model

FIGURE 8: The parametric-oriented FE model of engine structure.

$P_{4}$ : (eccentricity of the coolant inlet, initial value is $9 \mathrm{~mm}$ ) variations are considered to be within $45 \%$ of its initial value,

$P_{5}$ : (length of the thread engagement, initial value is $30 \mathrm{~mm}$ ) this factor may vary from $20 \mathrm{~mm}$ to $60 \mathrm{~mm}$,

$P_{6}$ : (pretightening sequence of the bolts, initial value is Sequence 1) Sequence 1 is 3-8-9-4-7-2-10-5-6-1, Sequence 2 is 3-9-8-2-4-10-7-1-5-6, and Sequence 3 is 3-8-2-9-4-7-1-10-5-6.

Due to the complex structural configuration and physical boundary conditions, the distortion simulation based on the above proposed FE model is a computationally intensive task. Moreover, the variation tendency of the dominant order of distortion is more desirable rather than a particular highly accurate calculation value during the parametric analysis. So, a simplified FE model is extracted from the previous detailed FE model by using feature suppression and deletion. Figure 8 shows the parametric-oriented FE model of engine structure. With this new model, the finite element method can be easily and economically be employed to deal with a large number of calculation steps.

Figures 9 and 10 provide details about the influence of the water jacket and pretightening parameters on the dominant order of distortion, respectively.

It can be seen that the thickness of the water jacket $\left(P_{1}\right)$ is a critical parameter concerning the 2 nd order of distortion. At the beginning, as $P_{1}$ increases, the distortion decreases significantly, that is, primarily due to the positive effect of the improvement of cooling conditions around the cylinder liner. However, when the thickness is larger than $9 \mathrm{~mm}$, the amplitude increases quickly, which indicates that the negative effect that follows with such increase of $P_{1}$ also results in weakening of the liner's stiffness. Therefore, a compromise for these two effects is necessary; that is, the thickness of $9 \mathrm{~mm}$ is optimal for $P_{1}$. In addition, the height of the coolant inlet $\left(P_{3}\right)$ also represents a considerable influence on the resulting of the 2 nd order of distortion. To acquire reasonable flow characteristic around the upper part of cylinder liner, the height of $55 \mathrm{~mm}$ is preferred for $P_{3}$. In contrast, slight distortion changes are observed for the other parameters $\left(P_{2}\right.$ and $P_{4}$ ); according to the variation tendency, the diameter and eccentricity of the coolant inlet should be selected as $28.8 \mathrm{~mm}$ and $9 \mathrm{~mm}$, respectively.

As for the pretightening process, it is obvious that a longer cylinder bolt (i.e., $60 \mathrm{~mm}$ ) and the $3 \mathrm{rd}$-assembly sequence should be adopted since the applied pretightening force would be better distributed within the cylinder structure. Based on this, the parameter adjustment for water jacket and pretightening process design is made to implement the distortion optimization, which is shown in Table 1. Table 2 lists the comparison of dominant order of distortions between the original and optimal design scheme. Figure 11 presents the comparison of the flow characteristic and pretightening stress distribution between the original and optimal design scheme.

In order to evaluate the improvement of the distortion level in optimal design, the problem of piston ring conformability to distorted cylinder bore is further considered in this 

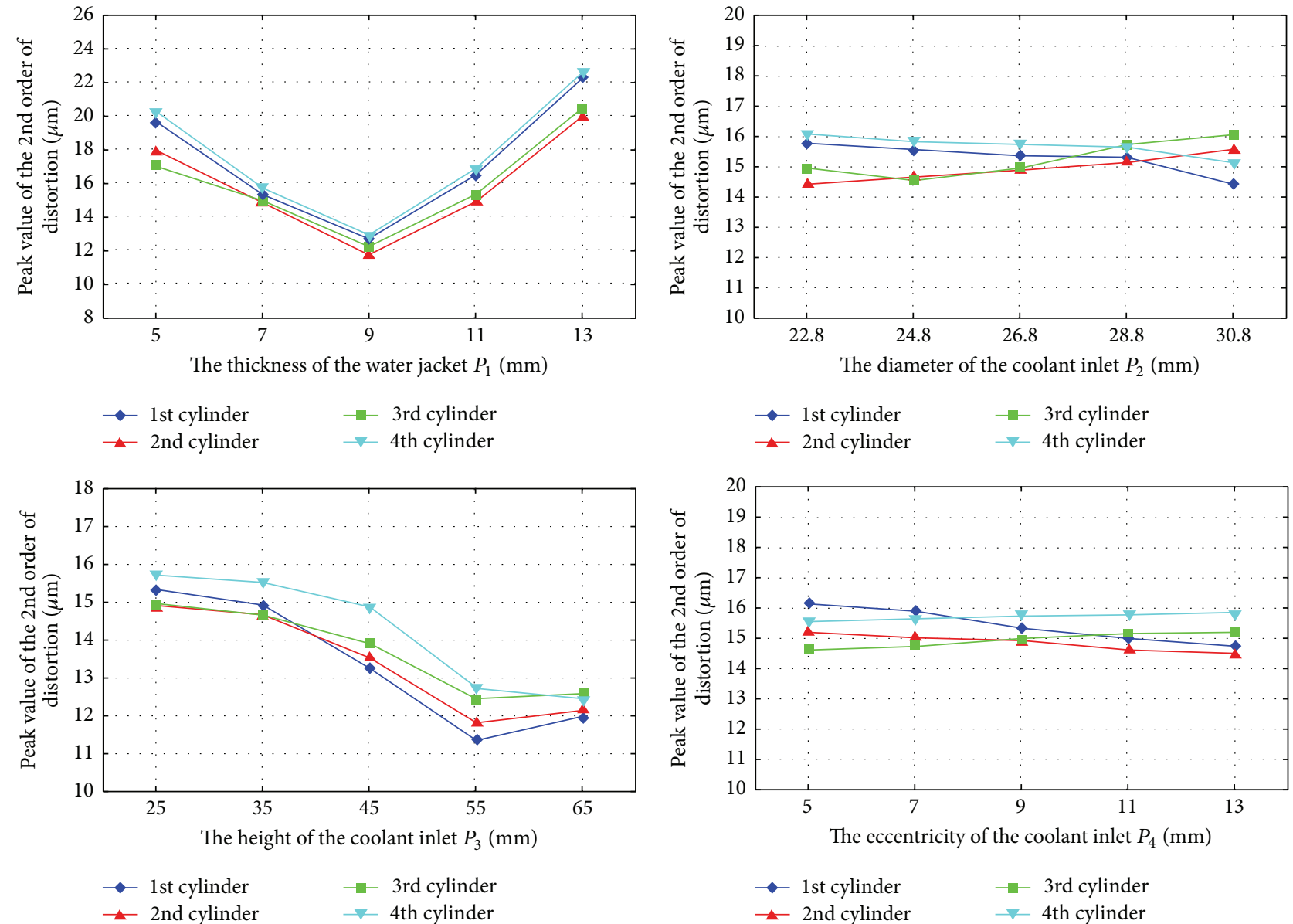

FIGURE 9: Influence of the water jacket parameters on the peak value of the 2nd order of distortion.
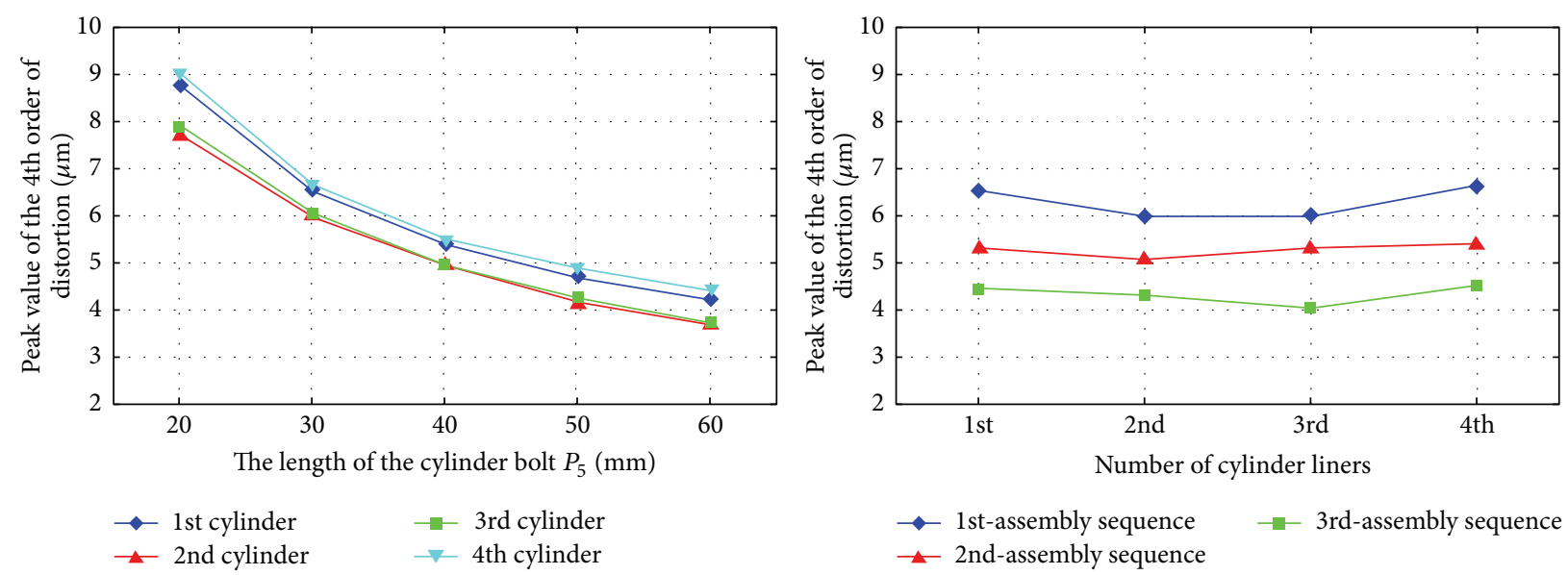

FIGURE 10: Influence of the pretightening parameters on the peak value of the 4th order of distortion.

TABLE 1: The parameter adjustment for water jacket and pretightening process design.

\begin{tabular}{lccccrr}
\hline \multirow{2}{*}{ Design parameters } & \multicolumn{3}{c}{ Water jacket } & \multicolumn{2}{c}{ Pretightening process } \\
& $P_{1}(\mathrm{~mm})$ & $P_{2}(\mathrm{~mm})$ & $P_{3}(\mathrm{~mm})$ & $P_{4}(\mathrm{~mm})$ & $P_{5}(\mathrm{~mm})$ & $P_{6}(\mathrm{sequence})$ \\
\hline Original & 7 & 26.8 & 25 & 9 & 30 & $3-8-9-4-7-2-10-5-6-1$ \\
Optimal & 9 & 28.8 & 55 & 9 & 60 & $3-8-2-9-4-7-1-10-5-6$ \\
\hline
\end{tabular}


TABLE 2: The comparison of the dominant order of distortion between the original and optimal design scheme.

\begin{tabular}{|c|c|c|c|c|c|c|c|c|}
\hline \multirow{2}{*}{ Maximum distortion $(\mu \mathrm{m})$} & \multicolumn{2}{|c|}{ 1st cylinder } & \multicolumn{2}{|c|}{ 2nd cylinder } & \multicolumn{2}{|c|}{ 3rd cylinder } & \multicolumn{2}{|c|}{ 4th cylinder } \\
\hline & 2nd order & 4 th order & 2nd order & 4 th order & 2nd order & 4 th order & 2nd order & 4 th order \\
\hline Original & 15.35 & 6.54 & 14.86 & 5.99 & 14.95 & 6.03 & 15.75 & 6.64 \\
\hline Optimal & 11.83 & 3.18 & 11.52 & 2.89 & 11.67 & 2.93 & 12.09 & 3.29 \\
\hline
\end{tabular}

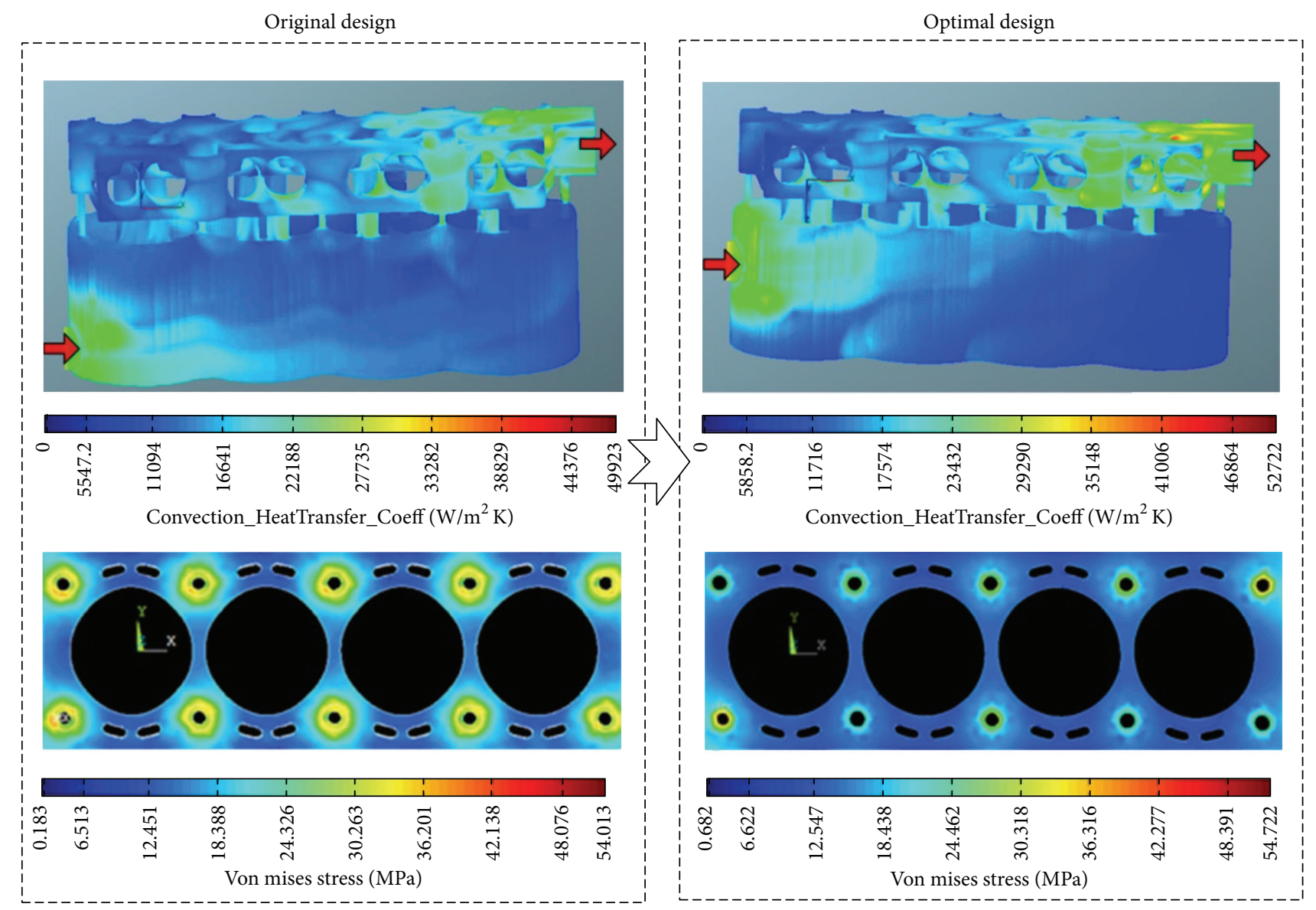

FIGURE 11: The comparison of the flow characteristic and pretightening stress distribution between the original and optimal design scheme.

paper: given FE data of cylinder liner distortions and a set of piston ring specifications, determine if the ring is fully conformed to the distorted cylinder bore under actual engine operation conditions. Till now, there are several bounds being widely adopted to estimate the piston ring conformability, namely, the analytically derived bounds (GOETZE bounds [9] and Dunaevsky bounds [11]), as well as the semiempirically derived bounds (Tomanik bounds [26]). Critical values of cylinder liner distortions are established for analyzed piston rings using either of the bounds $[9,11,26]$ in this paper. All the parameters utilized in these bounds are deducible from the piston ring specifications. Figure 12 demonstrates the comparison of different bounds for cylinder liner distortions.

By comparing the optimized distortion values listed in Table 2 with the critical values which are determined through the above stated bounds, it can be found that a much better solution is obtained in the optimal design scheme, because the distortions in optimal design are minimized to satisfy both the GOETZE and Dunaevsky bounds and approximates to the tightest Tomanik bounds.

As a result of the reduction of cylinder liner distortions, a bore profile closer to the perfectly circular cylinder liner is obtained. This provides an opportunity to further improve the operational performance of the piston group. Since the piston ring will achieve better sealing characteristics within a low distorted cylinder bore which leads to a reduction of both the oil consumptions and exhaust emissions. Meanwhile, the requirement for the pretightening of piston rings also diminishes, which means that it may be possible to obtain lower engine friction losses and fuel consumptions. 


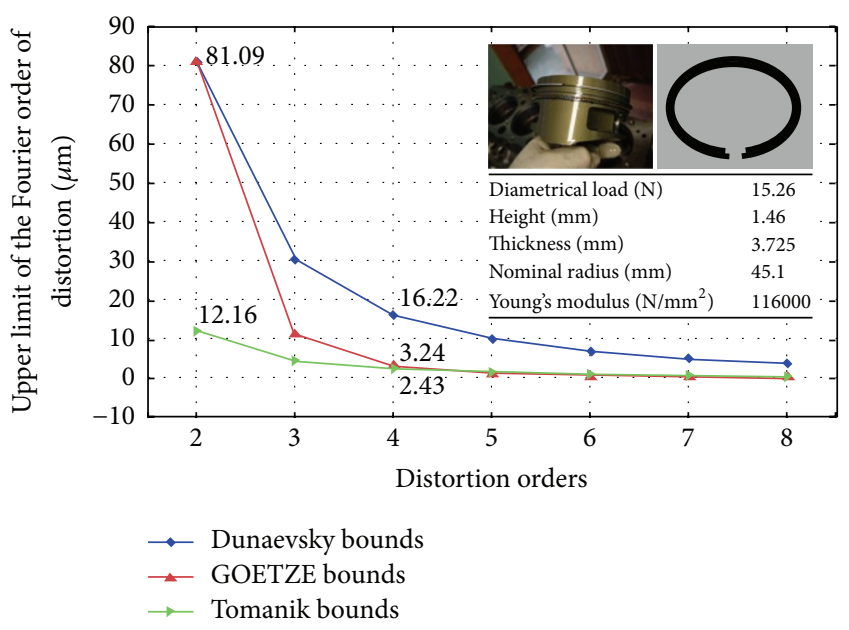

FIGURE 12: The comparison of different bounds for cylinder liner distortions.

\section{Conclusions}

This study is an initial attempt towards a computational framework for the distortion optimization of engine cylinder liner. Some conclusions are extracted as follows:

(1) Detailed simulation based on the combination of FEM and CFD is carried out to precisely capture the realistic distortions at any interest point of cylinder liner. Calculation results show that there are complex three-dimensional distortions arising in the engine operational process.

(2) The analysis methodology for spectrum characterization of bore distortions and various operational loads is developed and implemented successfully in this research. The unique feature of this method is its capability of distinguishing the relationship between the dominant order of distortion and special operational load. Analytical results indicate that the 2 nd- and 4thFourier orders are the dominant distortion orders. Moreover, the 2nd order of distortion is the most sensitive to the thermal load (temperature patterns) and the mechanical load (pretightening stress) is the most critical to the 4 th order of distortion.

(3) A parametric-oriented FE model is simplified from the previous detailed FE model by using feature suppression and deletion. The variation tendency of each dominant order of distortion is obtained through parametric analysis, and the optimal design scheme for water jacket and pretightening process is finally achieved based on these findings. Simulation results indicate that a much better solution is obtained by using this scheme.

\section{Competing Interests}

The authors declare that they have no competing interests.

\section{Acknowledgments}

The authors gratefully wish to acknowledge support by The National Natural Science Foundation of China under Grant no. 51505383, The China Postdoctoral Science Foundation under Grant no. 2015M580874, and The Fundamental Research Funds for the Central Universities under Grant no. $3102015 Z Y 002$.

\section{References}

[1] R. Keribar, Z. Dursunkaya, and M. F. Flemming, "Integrated model of ring pack performance," Journal of Engineering for Gas Turbines and Power, vol. 113, no. 3, pp. 382-389, 1991.

[2] R. Rabuté and T. Tian, "Challenges involved in piston top ring designs for modern SI engines," Journal of Engineering for Gas Turbines and Power, vol. 123, no. 2, pp. 448-459, 2001.

[3] T. Tian, "Dynamic behaviours of piston rings and their practical impact. Part 1: ring flutter and ring collapse and their effects on gas flow and oil transport," Proceedings of the Institution of Mechanical Engineers Part J: Journal of Engineering Tribology, vol. 216, no. 4, pp. 209-228, 2002.

[4] Y. R. Jeng, "Friction and lubrication analysis of a piston ring pack," SAE Paper 920492, 1992.

[5] R. Taylor, M. Brown, D. Thompson, and J. Bell, "The influence of lubrication rheology on friction in the piston ring pack," SAE Paper 941981, 1981.

[6] M.-T. Ma, I. Sherrington, and E. H. Smith, "Analysis of lubrication and friction for a complete piston-ring pack with an improved oil availability model: part 1: circumferentially uniform film," Proceedings of the Institution of Mechanical Engineers, Part J: Journal of Engineering Tribology, vol. 211, no. 1, pp. $1-15,1997$.

[7] D. C. Sun, "A thermal elastica theory of piston-ring and cylinder-bore contact," Journal of Applied Mechanics, vol. 58, no. 1, pp. 141-153, 1991.

[8] B. Y. Gintsburg, "Splitless-type piston rings," Russian Engineering Journal, vol. 48, no. 7, pp. 37-40, 1968.

[9] R. Müeller, "Conformability of piston rings to out-of-round bores," MTZ, vol. 31, no. 1, pp. 79-82, 1970.

[10] K. Luenne and R. Ziemb, “The GOETZE cylinder distortion measurement system and the possibilities of reducing cylinder distortions," SAE Paper 880142, 1988.

[11] V. V. Dunaevsky, "Analysis of distortions of cylinders and conformability of piston rings," Tribology Transactions, vol. 33, no. 1, pp. 33-40, 1990.

[12] V. Dunaevsky and J. Rudzitis, "Clarification of a semi-empirical approach in Piston ring-cylinder bore conformability prediction," Journal of Tribology, vol. 129, no. 2, pp. 430-435, 2007.

[13] A. Soua, M. Touratier, and L. Polac, "Computations of an engine to analyze cylinder distortion," Engineering Computations, vol. 16, no. 1, pp. 9-25, 1999.

[14] F. Maassen, F. Koch, M. Schwaderlapp et al., "Analytical and empirical methods for optimization of cylinder liner bore distortion," SAE Paper 2001-01-0569, 2001.

[15] S.-W. Chyuan, "Finite element simulation of a twin-cam 16valve cylinder structure," Finite Elements in Analysis and Design, vol. 35, no. 3, pp. 199-212, 2000. 
[16] V. Dunaevsky and S. Alexandrov, "Development of conformability model of piston rings with consideration of their threedimensional torsional distortions and Fourier series representation of cylinder bore geometry," SAE Technical Paper 200201-3131, 2002.

[17] M. H. Shojaefard, M. R. Ghaffarpour, A. R. Noorpoor, and S. Alizadehnia, "Thermomechanical analysis of an engine cylinder head," Proceedings of the Institution of Mechanical Engineers, Part D: Journal of Automobile Engineering, vol. 220, no. 5, pp. 627-636, 2006.

[18] S. N. Kurbet and S. R. Kumar, "Finite element modelling of piston-ring dynamics and blow-by estimation in a four-cylinder diesel engine," Proceedings of the Institution of Mechanical Engineers Part D-Journal of Automobile Engineering, vol. 221, no. 11, pp. 1405-1414, 2007.

[19] S.-S. Cho, C. S. Shin, C. S. Lee, H. Chang, and K. W. Lee, "Assessment of an engine cylinder head-block joint using finite element analysis," International Journal of Automotive Technology, vol. 11, no. 1, pp. 75-80, 2010.

[20] C.-C. Lee, K.-N. Chiang, W.-K. Chen, and R.-S. Chen, "Design and analysis of gasket sealing of cylinder head under engine operation conditions," Finite Elements in Analysis and Design, vol. 41, no. 11-12, pp. 1160-1174, 2005.

[21] G. Borman and K. Nishiwaki, "Internal-combustion engine heat transfer," Progress in Energy and Combustion Science, vol. 13, no. 1, pp. 1-46, 1987.

[22] W. Annand and T. H. Ma, "Instantaneous heat transfer rates to the cylinder head surface of a small compression ignition engine," Proceedings of the Institution of Mechanical Engineers, vol. 185, no. 10, pp. 976-988, 1970.

[23] G. Woschni and F. Anisits, "Experimental investigation and mathematical presentation of rate of heat release in diesel engines dependent upon engine operating conditions," SAE Paper 740086, 1974.

[24] A. Kaźmierczak, "Computer simulation of piston-piston ringcylinder liner coactions in combustion engines," Proceedings of the Institution of Mechanical Engineers Part D: Journal of Automobile Engineering, vol. 218, no. 12, pp. 1491-1501, 2004.

[25] Z. Han and R. D. Reitz, "Turbulence modeling of internal combustion engines using RNG k-e models," Combustion Science and Technology, vol. 106, no. 4, pp. 267-276, 1995.

[26] E. Tomanik, "Piston ring conformability in a distorted bore," SAE Technical Paper 960356, 1996. 


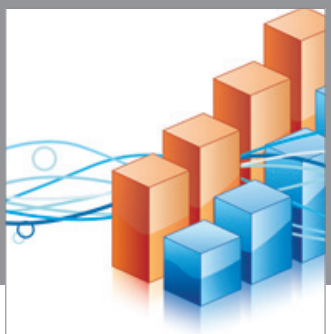

Advances in

Operations Research

vatem alat4

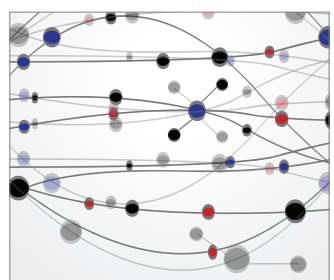

\section{The Scientific} World Journal
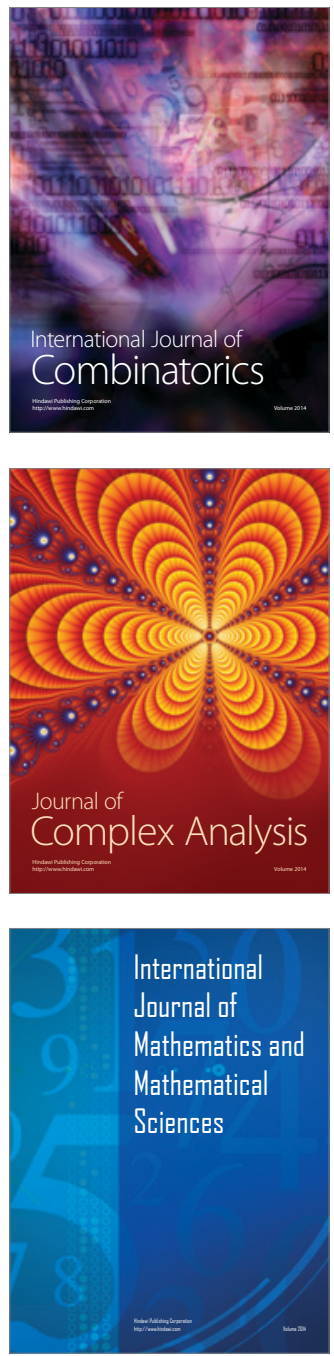
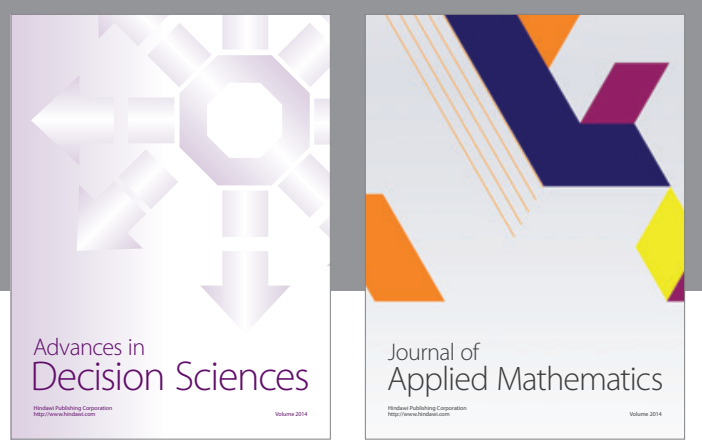

Algebra

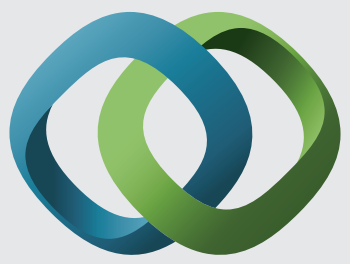

\section{Hindawi}

Submit your manuscripts at

http://www.hindawi.com
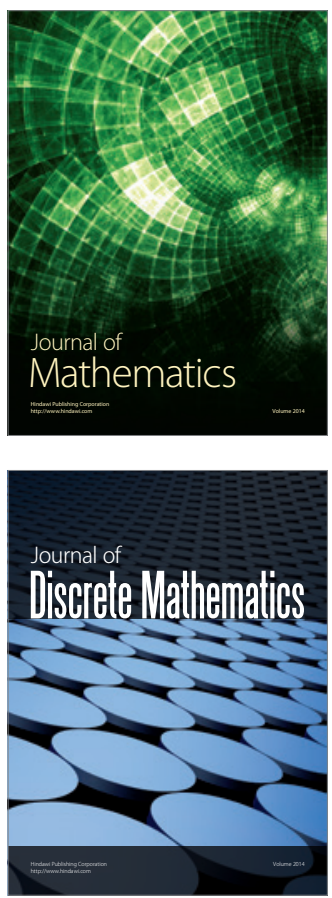

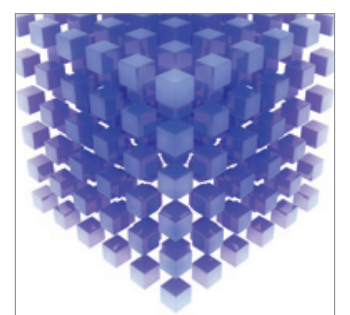

Mathematical Problems in Engineering
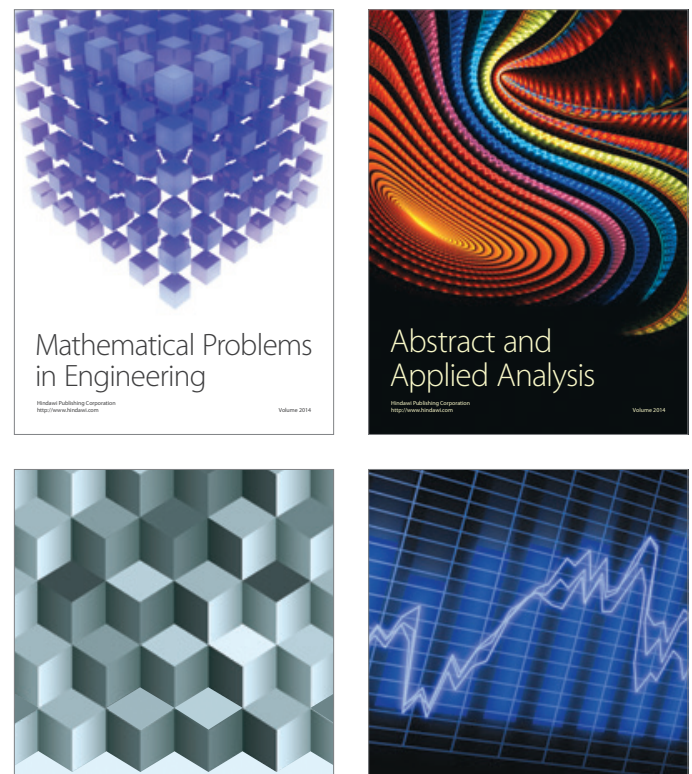

Journal of

Function Spaces

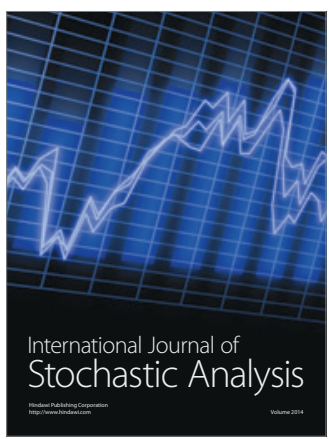

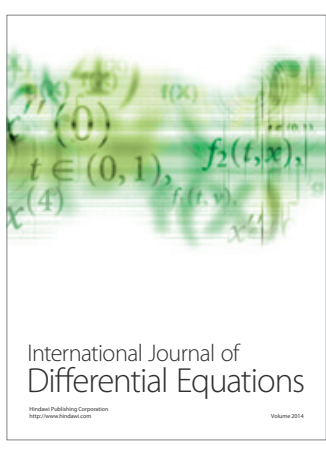
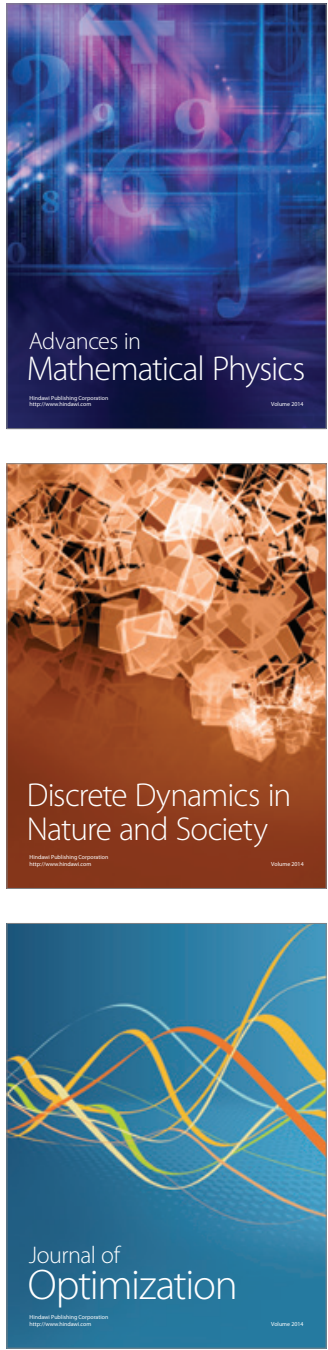